Article

\title{
Improved Three-Phase AFD Islanding Detection Based on Digital Control and Non-Detection Zone Elimination
}

\author{
Xinxin Zheng ${ }^{1}$, Rui Zhang ${ }^{1}$, Xi Chen ${ }^{2, *}$ and Nong Sun ${ }^{2}$ \\ 1 Automobile Engineering Technology Research Institution, Hefei University of Technology, Hefei 230009, \\ China; xinxin.zheng@hfut.edu.cn (X.Z.); zhr1622@126.com (R.Z.) \\ 2 State Grid Hefei Electric Power Supply Company, Hefei 230001, China; sunnong2006@163.com \\ * Correspondence: chenxi0019@126.com; Tel.: +86-0551-6388-3181
}

Received: 23 August 2018; Accepted: 10 September 2018; Published: 13 September 2018

\begin{abstract}
This paper proposes an improved active frequency drift (AFD) islanding detection method of a three-phase inverter. Different than the existing single-phase AFD method, in the three-phase system, the disturbance is added to the phase angle, which takes part in coordinate transformation calculations. Thus, the frequency drift of the three-phase reference current can be realized by the disturbance of the phase angle. It is unnecessary to add frequency drift to each phase respectively with the proposed method, which can simplify the control system. Furthermore, the non-detection zone can be eliminated by updating certain parameters; therefore, the detection method is sensitive. In this paper, the application of the proposed method in a digital control system is discussed in detail. The non-detection zone is analyzed, and an elimination method is proposed. Finally, the simulation and experimental results are given to verify the theoretical analysis.
\end{abstract}

Keywords: three-phase inverter; islanding detection; non-detection zone; zero-crossing correction; active frequency drift

\section{Introduction}

The three-phase grid-connected inverter plays an important role in the field of distributed power generation [1]. The islanding phenomenon would cause confusion in AC frequency, phase, and amplitude. Islanding detection is necessary for avoiding damage to electrical equipment and personal injury [2,3]. Islanding detection methods can be divided into passive and active methods. The passive methods detect the voltages, currents, and phases of the inverter. If one or more of them are not in the allowed range, islanding can be detected [4-8]. The non-detection zone (NDZ) is the main disadvantage of the passive methods. For solving the problem, an islanding detection method based on feature recognition technology is proposed in [5]. The features of the inverter system are identified. The vector model of the inverter features is established instead of the limited parameters in the traditional passive methods. Thus, the NDZ can be eliminated. However, comprehensive conditions should be taken into consideration. The feature recognition of the inverter system is complex.

The application of active islanding detection methods is more common. The active methods can be divided into grid variable variation-based methods and impedance estimation-based methods $[9,10]$. The principle and classification of the impedance estimation-based methods are discussed in [10]. In these methods, islanding is detected according to the variations at the power converter output impedance. These methods have the advantages of low current distortion and high detection speed [11-15]. However, false judgment and a complex control strategy limit the application of these methods. The grid variable variation-based methods can detect the islanding effect of a grid 
response on a small disturbance [16-23]. The methods based on frequency and voltage drift are very popular. However, to eliminate the NDZ, additional disturbance should be added. The current distortion cannot be avoided.

To decrease current distortion and eliminate the NDZ, a simplified power control strategy with islanding detection for a three-phase grid-connected photovoltaic inverter is proposed in [11]. Harmonic current is injected as the disturbance, which results in harmonic voltage on the local load. By transforming these voltages into the rotating reference frame, the DC component of these voltages can be detected. A low-pass filter is applied in this method, which would cause a time delay and the islanding would not be detected in time. A systematic phase-locked loop (PLL) modeling and design approach for evaluating the frequency-based islanding detection method is proposed in [19]. An input injection signal is added to the PLL. This method is sensitive to the control parameters. The system stability may be threatened. In [20], an active method based on voltage positive feedback is given. The method uses a sliding mode controller to detect the islanding effect of the photovoltaic system with string inverter. The active power perturbation has been applied only in deceleration mode, considering the disturbance definition in the inverter voltage control loop. In [21], a high-performance islanding search sequence technique is proposed. The output of the inverter can be seen as a voltage source. This method does not apply to an inverter in which the output is a current source.

According to the above analysis, this paper proposes an improved active frequency drift (AFD) method, which applies to the three-phase grid-connected inverter. The traditional AFD method can only be used for the single-phase inverter and there is an NDZ problem [24-26]. The existing improved methods, such as automatic phase-shift and AFD with positive feedback, cannot be used in the three-phase systems [27-30]. The proposed method can eliminate the NDZ, and the current distortion is low. The frequency disturbance is added to the output of the PLL. Thus, the phase angle, which takes part in the coordinate transformation, tends to change the frequency of the current reference. Furthermore, the NDZ can be totally eliminated by certain parameter updating.

This paper is organized as follows. In Section 2, the principle of the proposed method is introduced. Section 3 analyzes the cause of NDZ. In Section 4, the improved method, which can eliminate the NDZ, is given. Finally, Section 5 shows the simulation and experimental results of the proposed islanding detection method to verify the theoretical analysis.

\section{Three-Phase AFD Method}

\subsection{Principle of the Three-Phase AFD Method}

Figure 1 shows the principle of the three-phase AFD method. In Figure $1 \mathrm{a}, e_{\mathrm{a}}, e_{\mathrm{b}}$, and $e_{\mathrm{c}}$ are the grid voltages. $Z_{\mathrm{a}}, Z_{\mathrm{b}}$ and $Z_{\mathrm{c}}$ are the line impedances. In the islanding detection, they can be ignored. Thus, $e_{\mathrm{a}}, e_{\mathrm{b}}, e_{\mathrm{c}}$ and the voltages $e_{\mathrm{as}}, e_{\mathrm{bs}}, e_{\mathrm{cs}}$ are the same. In the space vector pulse width modulation (SVPWM) control, the phase angle $\theta_{0}$, which takes part in the coordinate transformation, is generated by PLL [31]. In the dashed box, the disturbed angle $\theta_{0}{ }^{\prime}$ takes part in the coordinate transformation from $i_{\mathrm{q}}{ }^{*}, i_{\mathrm{d}}{ }^{*}$ to $i_{\mathrm{dra}}{ }^{*}, i_{\mathrm{drb}}{ }^{*}, i_{\mathrm{drc}}{ }^{*} \cdot \theta_{0}$ takes part in the coordinate transformation from $i_{\mathrm{dra}}{ }^{*}, i_{\mathrm{drb}}{ }^{*}, i_{\mathrm{drc}}{ }^{*}$ to $i_{\mathrm{drq}}{ }^{*}, i_{\mathrm{drd}}{ }^{*}$. The three-phase current reference $i_{\mathrm{dra}}{ }^{*}, i_{\mathrm{drb}}{ }^{*}, i_{\mathrm{drc}}{ }^{*}$ is shown in Figure $1 \mathrm{~b}, \mathrm{c} . \theta_{0}{ }^{\prime}$ does not take part in other coordinate transformations to avoid additional disturbances.

In Figure 1b,c the waveforms from top to bottom are, respectively, the current reference without disturbance, the phase angle, and the current reference with disturbance. The disturbance can increase or decrease the current frequency after the inverter is disconnected from the grid. $\theta_{0}$ is the output of the PLL. It changes from $-\pi$ to $\pi$ with the grid frequency. $\theta_{0}{ }^{\prime}$ is the phase angle after AFD. It changes from $-\pi$ to $\pi$ with the disturbed frequency. To correct the frequency when the inverter is connected to the grid, zero-crossing correction (ZCC) is necessary.

In Figure $1 b$, the disturbance tends to increase the current frequency. ZCC operates when $\theta_{0}{ }^{\prime}$ is 0 and $\theta_{0}$ is less than 0 . In this condition, $\theta_{0}^{\prime}$ does not change from 0 until $\theta_{0}$ reaches 0 . The slope of $\theta_{0}{ }^{\prime}$ is higher than that of $\theta_{0}$. At time $t_{3}, \theta_{0}{ }^{\prime}$ finishes a liner-changed cycle. During $t_{3}$ to $t_{4}, \theta_{0}{ }^{\prime}$ keeps 0 . 
At time $t_{4}, \theta_{0}$ finishes a liner-changed cycle, which is just the grid cycle $T$. After $t_{4}, \theta_{0}{ }^{\prime}$ and $\theta_{0}$ begin to increase from 0 with different slopes.

Similarly, in Figure 1c, the disturbance tends to decrease the current frequency. ZCC operates when $\theta_{0}$ is 0 and $\theta_{0}{ }^{\prime}$ is less than 0 . At the zero-crossing time, $\theta_{0}{ }^{\prime}$ is enforced as 0 .

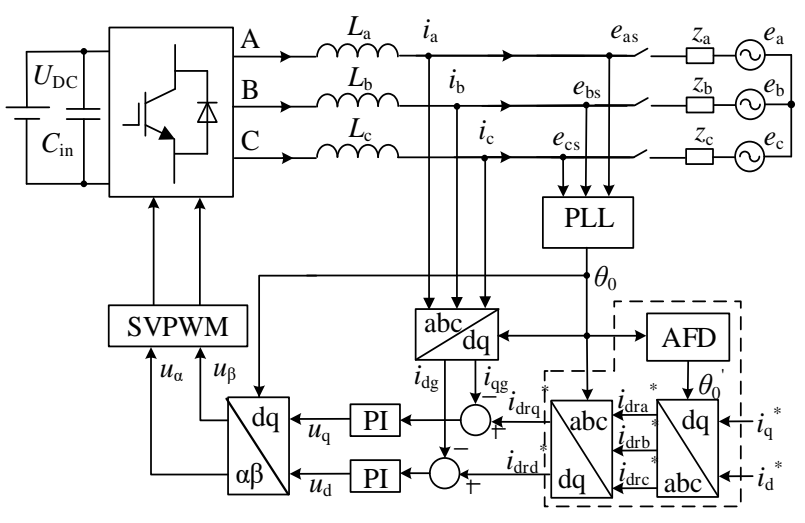

(a)

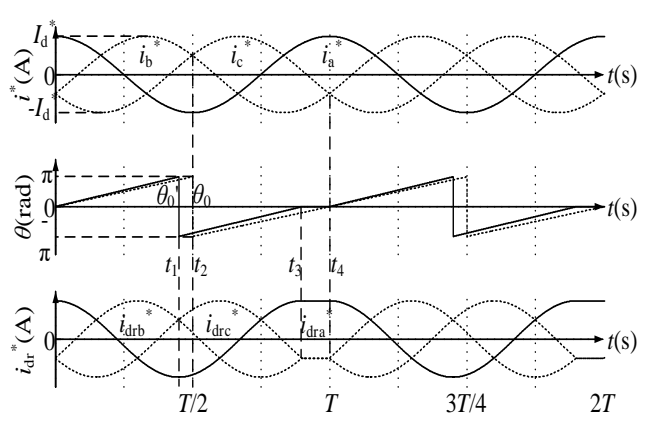

(b)

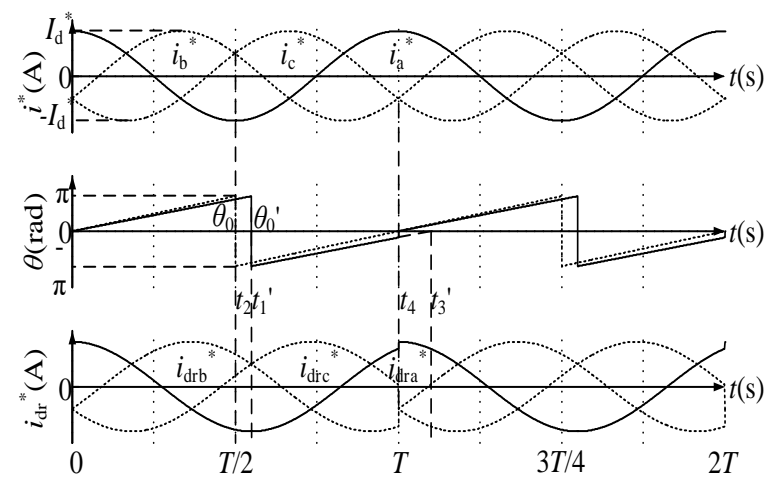

(c)

Figure 1. Principle of the three-phase active frequency drift (AFD) method. (a) The control diagram. (b) The disturbance tending to increase the current frequency. (c) The disturbance tending to decrease the current frequency.

\subsection{AFD Control Strategy in the Digital Control System}

According to Figure 1, the aim of the phase angle disturbance is to realize frequency drift. When the inverter works normally, the frequency achieved by the PLL is the grid frequency. In each grid cycle, the frequency disturbance is a fixed value. It is imposed on the grid frequency and will not be accumulated. After the inverter is disconnected from the grid, ZCC still works. If the local load is resistive, the phases of the AC current and voltage are the same. The zero-crossing times of $\theta_{0}{ }^{\prime}$ and $\theta_{0}$ are the same. ZCC will not force the frequency correction of $\theta_{0}{ }^{\prime}$. Thus, the current frequency changes with the disturbance. In addition, the voltage frequency will change and it can be detected by the PLL. In the next cycle, the disturbance will be accumulated.

In the digitally-controlled three-phase inverter system, the frequency is calculated by the slope of the phase angle, which can be expressed as follows:

$$
f=\frac{\omega_{0}}{2 \pi}=\frac{1}{2 \pi} \frac{d \theta_{0}}{d t}=\frac{1}{2 \pi} \frac{\Delta \theta}{\Delta t}
$$

In the digital controller, the phase angle $\theta_{0}$ is calculated in every switching cycle. $T_{c}$ is the switching cycle. Thus, $\Delta t$ is $T_{c}$ and $\Delta \theta$ is the difference of $\theta_{0}$ in the two adjacent calculations. The simplest filtering algorithm is applied. In fact, $\Delta \theta$ is the average value. It can be expressed as follows: 


$$
\Delta \theta=\frac{1}{k} \sum_{i=1}^{k} \Delta \theta_{i}
$$

where $k$ is the number of calculations.

Figure 2 shows the change of the phase angle after the inverter gets disconnected from the grid at $t_{0}$. The local load is resistive. The grid frequency is $f_{0}$. The disturbance is $\Delta f_{0}$. If the disturbance tends to increase the current frequency, $\Delta f_{0}$ is larger than 0 . On the contrary, $\Delta f_{0}$ is less than 0 . In each $k$ times of the switching cycle, the average value $\Delta \theta$ and the AC voltage frequency are calculated. In the next $k$ times of the switching cycle, the disturbance $\Delta f_{0}$ is added to the AC voltage frequency. The disturbed frequency is the frequency of the current reference. As a result, the disturbance cycle is $k T_{c}$. Before $t_{0}$, the AC voltage frequency is always $f_{0}$. Therefore, the frequency of the current reference is always $f_{0}+\Delta f_{0}$.

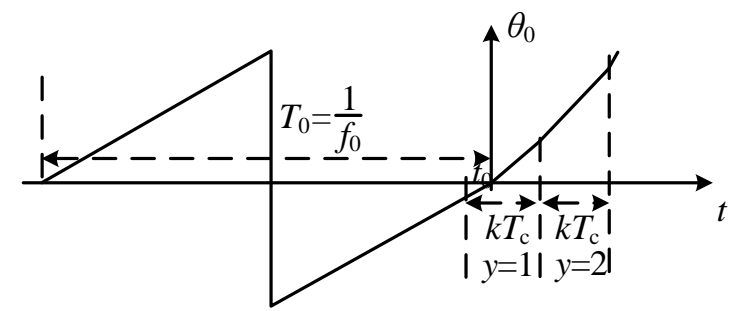

(a)

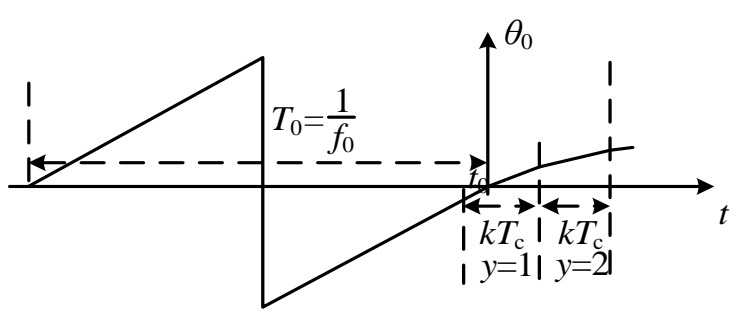

(b)

Figure 2. Change of the phase angle after the inverter is disconnected from the grid. (a) The disturbance tending to increase the current frequency. (b) The disturbance tending to decrease the current frequency.

Because of ZCC, the real current frequency is still $f_{0}$. After $t_{0}$, the AC voltage frequency changes with the disturbance. $y$ is the number of disturbance cycles after $t_{0}$. At time $t_{0}, y$ is 1 . In the area where $y$ is 1 , the AC voltage frequency is not the grid frequency. According to (1), in this cycle, the AC voltage frequency can be expressed as follows:

$$
f_{O F F(y=1)}=\frac{(w-1) f_{0}+(k-w+1)\left(f_{0}+\Delta f_{0}\right)}{k} \quad(1 \leq w \leq k)
$$

where $w$ is the number of switching cycles at $t_{0}$. It is larger than or equal to 1 and less than or equal to $k$. Thus, the range of $f_{\text {OFF }(y=1)}$ is $\left[f_{0}+\Delta f_{0} / k, f_{0}+\Delta f_{0}\right]$. If $f_{\text {OFF }(y=1)}$ is still in the allowed range, the disturbance $\Delta f_{0}$ would be added to $f_{O F F(y=1)}$ instead of $f_{0}$. In the next disturbance cycle, the frequencies of the AC current and voltage both are

$$
f_{O F F(y=2)}=f_{O F F(y=1)}+\Delta f_{0}
$$

The frequency accumulation does not stop until the AC voltage frequency exceeds the allowed range. However, in some certain conditions, NDZ would occur, which will be analyzed in the next section.

\subsection{Comparison between the Existing Method and the Proposed Method}

In [24], a typical single-phase AFD method is described in detail. A current waveform distortion to the original reference current of the inverter has been injected to realize the frequency drift. Taking the condition where the disturbance tends to increase the current frequency, for example, Figure 3 shows the application of the existing method in the three-phase system. The waveforms from top to bottom respectively are the current reference without disturbance, the injected waveform, and the current reference with disturbance. By introducing a zero conduction time at the end of each cycle, the phase angle of the fundamental component of the current is shifted. Comparing Figures 3 and $1 \mathrm{~b}$, 
it can be seen clearly that frequency drift should be added to each phase respectively with the existing method. With the proposed method, the control system can be simplified.

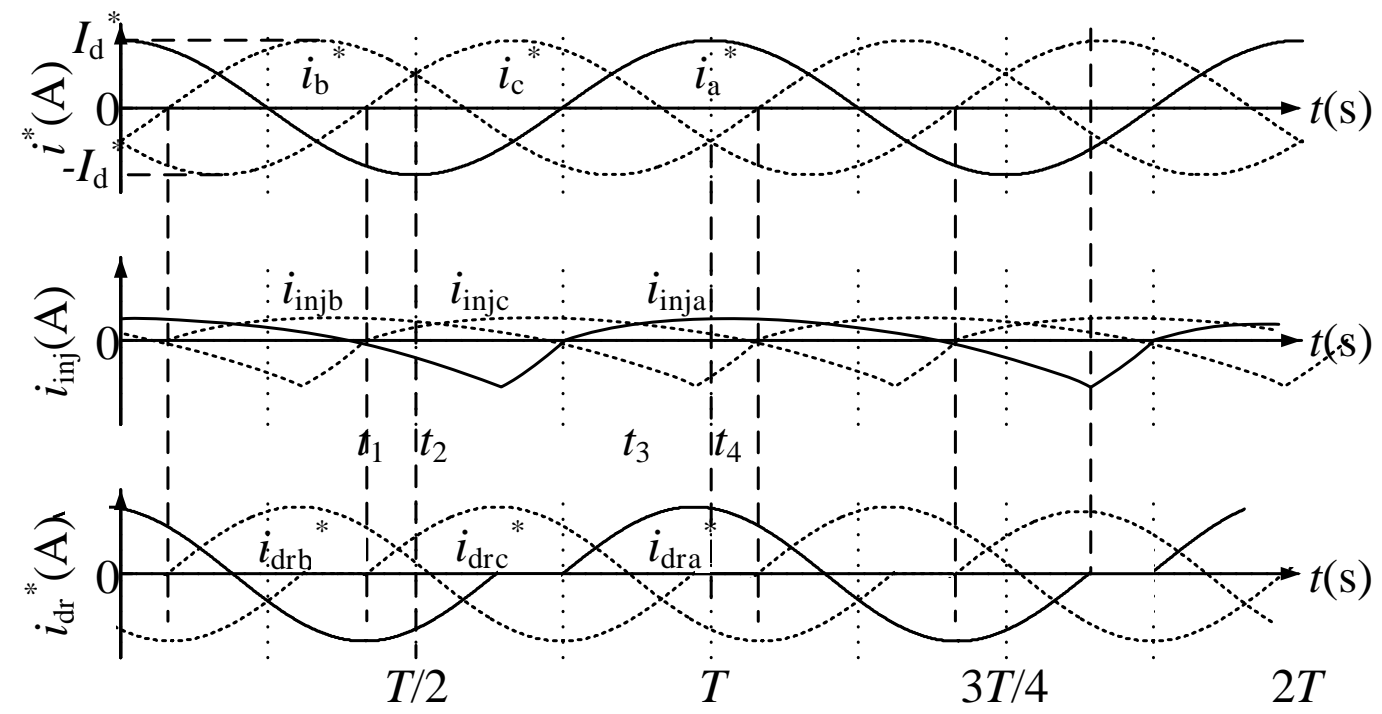

Figure 3. Application of the existing method in the three-phase system.

\section{Analysis of the Non-Detection Zone}

\subsection{Detection Process and Parameter Calculations}

The local load can be seen as a parallel structure of the resistance, inductance and capacitance, which can be defined as RLC parallel load. The impedance angle of it can be expressed as follows:

$$
\varphi_{\text {load }}=\arctan Q_{R L C}\left(\frac{f_{r}}{f}-\frac{f}{f_{r}}\right)
$$

where $Q_{R L C}$ is the quality factor and $f_{r}$ is the resonant frequency. They can be expressed as follows:

$$
\begin{gathered}
Q_{R L C}=\frac{R}{2 \pi f_{r} L}=2 \pi R f_{r} C=R \sqrt{\frac{C}{L}} \\
f_{r}=\frac{1}{2 \pi \sqrt{L C}}
\end{gathered}
$$

If the AC voltage frequency $f$ is the same as $f_{r}, \varphi_{\text {load }}$ is 0 and the local load is resistive. If $f$ is less than $f_{r}, \varphi_{\text {load }}$ is positive and the local load is inductive. If $f$ is larger than $f_{r}, \varphi_{\text {load }}$ is negative and the local load is capacitive.

According to Figure 1, when the inverter works normally, the phase angle of the reference current in the $(i+1)$ switching cycle can be expressed as follows:

$$
\theta_{i+1}{ }^{\prime}=\theta^{\prime}{ }_{i}+2 \pi\left(f_{0}+\Delta f_{0}\right) T_{\mathcal{C}}
$$

The AC current phase difference between the two adjacent switching cycles is

$$
\Delta \theta_{i}^{\prime}=\Delta \theta_{i}+2 \pi \Delta f_{0} T_{\mathcal{c}} \quad(1 \leq i \leq k)
$$

In Figure 1, the difference between $\theta_{0}{ }^{\prime}$ and $\theta_{0}$ is $\Delta \sigma . \Delta \sigma$ changes from 0 to the maximum value in each grid cycle. At the end of the cycle, $\Delta \sigma$ is forced to 0 again because of ZCC. The range of $\Delta \sigma$ can be expressed as follows: 


$$
0 \leq \Delta \sigma \leq \frac{2 \pi \Delta f_{0}}{f_{0}+\Delta f_{0}}
$$

Because of the digital filtering, the calculation of the AC voltage frequency needs $k$ times of the switching cycle; i.e., the AC voltage frequency is updated at the end of each disturbance cycle. After the inverter is disconnected from the gird at time $t_{0}$, the phase difference between the AC voltage and current is determined by the impedance angle $\varphi_{\text {load }}$. In the first switching cycle after $t_{0}$, the phase angle of the AC current is $\theta_{c}+\Delta \theta_{i}{ }^{\prime}$, while the phase angle of the AC voltage is $\theta_{c}+\Delta \theta_{i}{ }^{\prime}+\varphi_{\text {load }(y=1)}$. The AC voltage phase difference between this and the previous switching cycles is as follows:

$$
\Delta \theta_{w}=\Delta \theta_{i}{ }^{\prime}+\varphi_{\text {load }(y=1)}+\Delta \sigma \quad(i=w)
$$

According to (2) and (11), the average AC voltage phase difference of the adjacent switching cycles in the condition that $y$ is 1 can be expressed as follows:

$$
\Delta \theta_{\text {OFF }(y=1)}=\frac{1}{k}\left(\sum_{i=1}^{w-1} \Delta \theta_{i}+\sum_{i=w}^{k} \Delta \theta_{i}{ }^{\prime}+\varphi_{\text {load }(y=1)}+\Delta \sigma\right)
$$

Figure 4 shows the relationship among $\Delta \theta, \Delta \theta_{O F F}$, and the inverter working conditions. $\Delta \theta$ is $2 \pi T_{c} f_{0}$. It is clamped by the grid frequency. The allowed range is $\left[2 \pi T_{c} f_{0 \min }, 2 \pi T_{c} f_{0 \max }\right] . \Delta \theta_{\text {OFF }}$ is influenced by the local load. The inverter does not stop working until $\Delta \theta_{O F F}$ exceeds the range $\left[2 \pi T_{c} f_{0 \min }, 2 \pi T_{c} f_{0 \max }\right.$ ]. If the inverter has approached the steady state and $\Delta \theta_{O F F}$ is still in the allowed range, the islanding cannot be detected.

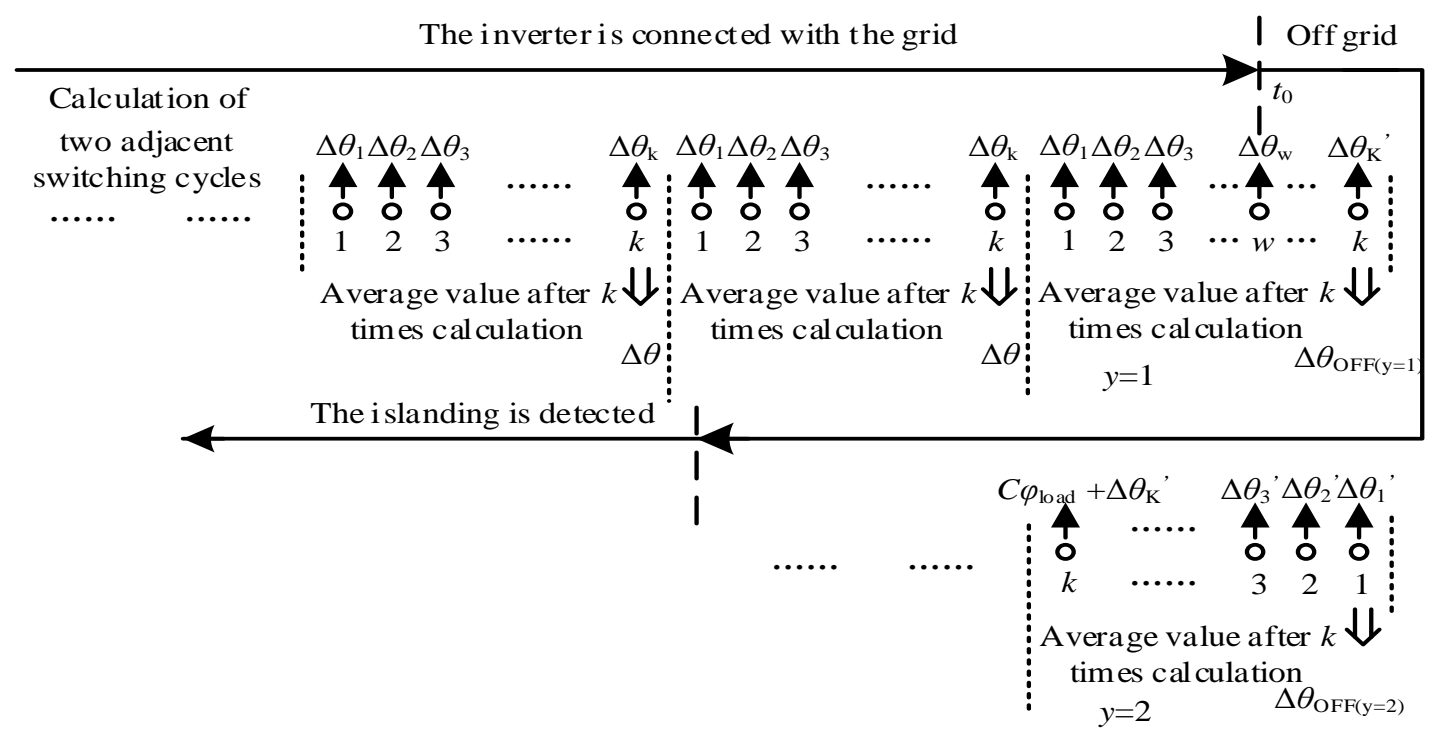

Figure 4. The relationship of $\Delta \theta, \Delta \theta_{O F F}$, and the inverter working conditions.

Taking (9) into (12), $\Delta \theta_{\operatorname{OFF}(y=1)}$ can be simplified as follows:

$$
\Delta \theta_{\text {OFF }(y=1)}=\theta_{\text {initial }}+\frac{\varphi_{\text {load }(y=1)}}{k}
$$

where $\theta_{\text {initial }}$ and $\varphi_{\text {load }(y=1)}$ can be expressed as follows:

$$
\begin{gathered}
\theta_{\text {initial }}=\Delta \theta+\frac{2 \pi \Delta f_{0} T_{\mathcal{c}}(k-w+1)+\Delta \sigma}{k} \quad(1 \leq w \leq k) \\
\varphi_{\text {load }(y=1)}=\arctan Q_{R L C}\left(\frac{f_{r}}{f_{0}+\Delta f_{0}}-\frac{f_{0}+\Delta f_{0}}{f_{r}}\right)
\end{gathered}
$$


After the parameters $\Delta \theta_{\operatorname{OFF}(y=1)}, \Delta \theta_{\operatorname{OFF}(y=2)}$, and $\Delta \theta_{\operatorname{OFF}(y=3)}$ are calculated in turn, the general expression can be given as

$$
\Delta \theta_{O F F(y=n+1)}=\Delta \theta_{O F F(y=n)}+2 \pi \Delta f_{0} T_{c}+\frac{B_{p}}{k} \varphi_{\operatorname{load}(y=n+1)}
$$

where $B_{p}$ represents the phase changing condition of the $A C$ voltage in the area that $y$ is $n+1$. If the phase of the AC voltage changes suddenly, $B_{p}$ is 1 ; otherwise, $B_{p}$ is $0 . \varphi_{\text {load }(y=n+1)}$ is the phase angle of mutation. It can be expressed as follows:

$$
\varphi_{\text {load }(y=n+1)}=\arctan Q_{R L C}\left(\frac{f_{r}}{f_{n}+\Delta f_{0}}-\frac{f_{n}+\Delta f_{0}}{f_{r}}\right)
$$

where $f_{n}$ is the $\mathrm{AC}$ voltage frequency calculated in the previous disturbance cycle. It can be expressed as follows:

$$
f_{n}=\frac{\Delta \theta_{O F F(y=n)}}{2 \pi T_{\mathcal{C}}}
$$

\subsection{Cause of the Non-Detection Zone}

Figure 5 shows the change of $\theta_{0}$ and $\theta_{0}{ }^{\prime}$ in the condition where the disturbance tends to increase the current frequency. The inverter gets disconnected from the grid at time $t_{0}$. According to the principle of ZCC, when $\theta_{0}{ }^{\prime}$ reaches 0 and $\theta_{0}$ is less than $0, \theta_{0}{ }^{\prime}$ does not stop increasing until $\theta_{0}$ reaches 0 . After $t_{0}, \theta_{0}$ is the phase angle of the AC voltage and $\theta_{0}{ }^{\prime}$ is the phase angle of the AC current. In Figure $5 \mathrm{a}$, the local load is inductive. $\theta_{0}$ is ahead of $\theta_{0}{ }^{\prime}$. It is impossible that $\theta_{0}{ }^{\prime}$ is 0 while $\theta_{0}$ is less than 0 . Therefore, $\theta_{0}{ }^{\prime}$ will not be corrected at the zero-crossing time. In the area that $y$ is $1, \theta_{0}$ changes suddenly and $B_{p}$ is 1 . According to (13), $\Delta \theta_{O F F(y=1)}$ is larger than $\Delta \theta$. It means that the calculated frequency of the $\mathrm{AC}$ voltage increases. In the areas that $\mathrm{y}$ is larger than $1, B_{p}$ is always 0 . According to (16), $\Delta \theta_{\operatorname{OFF}(y=n+1)}$ is always larger than $\Delta \theta_{\operatorname{OFF}(y=n)}$. It means that the frequency disturbance would be accumulated. The islanding can be quickly detected in a few disturbance cycles. The NDZ will not occur.

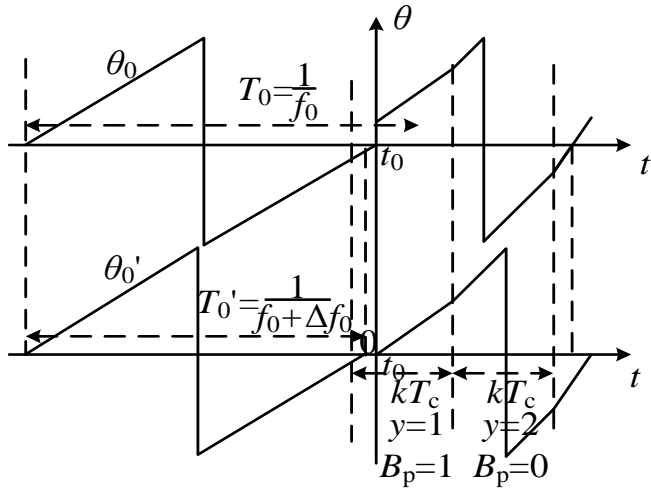

(a)

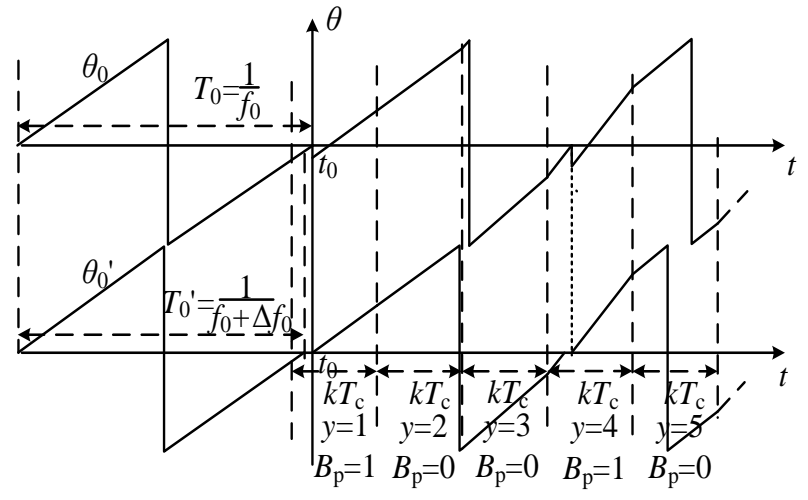

(b)

Figure 5. The change of $\theta_{0}$ and $\theta_{0}{ }^{\prime}$ in the condition that the disturbance tending to increase the current frequency. (a) The inductive load. (b) The capacitive load.

In Figure $5 b$, the local load is capacitive. In the area that $y$ is $1, \theta_{0}$ changes suddenly and $B_{p}$ is 1. The frequency of the AC current is $f_{0}+\Delta f_{0}$. According to (13), it is possible that $\Delta \theta_{O F F(y=1)}=\Delta \theta$. Thus, the calculated $\mathrm{AC}$ voltage frequency in this disturbance cycle is still the grid frequency $f_{0}$. In the area that $y$ is 2 , the frequency of the $\mathrm{AC}$ current is still $f_{0}+\Delta f_{0} . B_{p}$ is 0 . According to (16), $\Delta \theta_{\operatorname{OFF}(y=2)}$ is larger than $\Delta \theta_{\operatorname{OFF}(y=1)}$. The calculated AC voltage frequency in this disturbance cycle is $f_{0}+\Delta f_{0}$. If the frequency is still in the allowed range, the inverter keeps on working. In the area that $y$ is 3 , the frequency of the AC current $f_{3}$ is $f_{0}+2 \Delta f_{0}$. The change value of $\theta_{0}$ from $\pi$ to $-\pi$ is $2 \pi$. The effect 
of this change is not sudden. Therefore, $B_{p}$ is $0 . \Delta \theta_{O F F(y=3)}$ is larger than $\Delta \theta_{O F F(y=2)}$. In the area that $y$ is $4, \theta_{0}{ }^{\prime}$ is corrected by ZCC. $B_{p}$ is 1 . According to (16), $\Delta \theta_{\text {OFF ( } y=4)}$ is less than $\Delta \theta_{O F F(y=3)}$. The difference between them is $\left|\varphi_{\text {load }(y=4)} / k\right|$. Furthermore, the decrease of $\theta_{0}$ in the area that $y$ is 4 is larger than the area that $y$ is $1 . f_{3}$ is larger than $f_{0}$. According to (15) and (17), $\varphi_{\text {load }(y=4)}$ is larger than $\varphi_{\text {load }(y=1)}$. It is possible that $\Delta \theta_{\operatorname{OFF}(y=4)}$ is the same as $\Delta \theta$; i.e., the disturbance accumulation would be offset by the lagging of the $\mathrm{AC}$ voltage phase angle. In the next zero-crossing time, the same condition would happen again and the islanding would not be detected.

Considering the common situation, in the area that $y$ is $x, \Delta \theta_{O F F(y=x)}$ is the same as $\Delta \theta$. In the process of $y=1$ to $y=x, B_{p}$ is 1 in the conditions that $y$ respectively is 1 and $x$. In the other areas, $B_{p}$ is 0 . According to (16), the cumulative calculation of $\Delta \theta_{\operatorname{OFF}(y=x)}$ can be expressed as follows:

$$
\begin{gathered}
\Delta \theta_{O F F(y=x-1)}=\theta_{\text {initial }}+\frac{\varphi_{\text {load }(y=1)}}{k}+2 \pi \Delta f_{0} T_{\mathcal{c}}(x-2) \\
\Delta \theta_{O F F(y=x)}=\Delta \theta_{O F F(y=x-1)}+2 \pi \Delta f_{0} T_{\mathcal{c}}+\frac{\varphi_{\text {load }(y=x)}}{k}=\Delta \theta=2 \pi f_{0} T_{\mathcal{C}}
\end{gathered}
$$

where $\varphi_{\text {load }(y=x)}$ can be expressed as

$$
\varphi_{\text {load }(y=x)}=\arctan Q_{R L C}\left(\frac{2 \pi T_{c} f_{r}}{\Delta \theta_{O F F(y=x-1)}+2 \pi T_{c} \Delta f_{0}}-\frac{\Delta \theta_{O F F(y=x-1)}+2 \pi T_{c} \Delta f_{0}}{2 \pi T_{c} f_{r}}\right)
$$

The requirement of the NDZ is that the cumulative disturbance cannot exceed the allowed range. In the process of $y=1$ to $y=x$, the disturbance has been accumulated $x-2$ times. Therefore, the requirement of $x$ is

$$
x-2<\frac{f_{0 \max }-f_{0 \min }}{\Delta f_{0}}
$$

Another requirement of $x$ is that the AC current phased angle should be corrected by the ZCC, which can be expressed as follows:

$$
2 \pi k T_{c} \sum_{n=1}^{x} f_{n}>2 \pi
$$

Then, (22) and (23) can be combined and simplified as follows:

$$
\left\{\begin{array}{l}
x<2+\frac{f_{0 \max }-f_{0 \min }}{\Delta f_{0}} \\
x>\frac{\Delta f_{0}-2 f_{0}+\sqrt{\left(2 f_{0}-\Delta f_{0}\right)^{2}-8 \Delta f_{0}{ }^{2}+8 \Delta f_{0} / T_{c} k}}{2 \Delta f_{0}}
\end{array}\right.
$$

The left term should be less than the right term. As a result, if the NDZ occurs, the range of the disturbance $\Delta f_{0}$ can be expressed as follows:

$$
\left\{\begin{array}{l}
\Delta f_{0}<\frac{-g_{f}-\sqrt{g_{f}^{2}-64 f_{0}\left(f_{0 \max }-f_{0 \min }\right)}}{16} \\
\Delta f_{0}>\frac{-g_{f}+\sqrt{g_{f}{ }^{2}-64 f_{0}\left(f_{0 \max }-f_{0 \min }\right)}}{16}
\end{array}\right.
$$

where $g_{f}$ can be expressed as follows:

$$
g_{f}=3\left(f_{0 \max }-f_{0 \min }\right)+8 f_{0}+4 / T_{c} k
$$

According to the standard GBT $15945-2008, f_{0 \max }$ is $50.5 \mathrm{~Hz}$ and $f_{0 \min }$ is $49.5 \mathrm{~Hz}$. To improve the detection speed, $k T_{c}$ should be shorter than $T_{0}$. The switching frequency is $5 \mathrm{kHz}$. Thus, $k$ should be less than 100. In this paper, $k$ is $20, f_{0}$ is $50 \mathrm{~Hz}$, and $T_{\mathcal{C}}$ is $1 / 5000 \mathrm{~s}$. According to (25), if the NDZ occurs, $\Delta f_{0}$ should be less than $0.167 \mathrm{~Hz}$ or larger than $74.45 \mathrm{~Hz}$. 
If $\Delta f_{0}$ is $0.1 \mathrm{~Hz}$, according to (24), the range of $x$ is 4.97 to 12 . Islanding is more likely to happen when the difference between $\Delta \theta_{\operatorname{OFF}(y=x)}$ and $\Delta \theta$ is less. In this condition, $\Delta \sigma$ is $0, w$ is $k$, and $x$ is the minimum integer, which is 5 . Thus, the NDZ can be achieved, which is the shadow area in Figure 6 . Similarly, in conditions where the disturbance tends to decrease the current frequency-when the local load is inductive- the NDZ would occur.

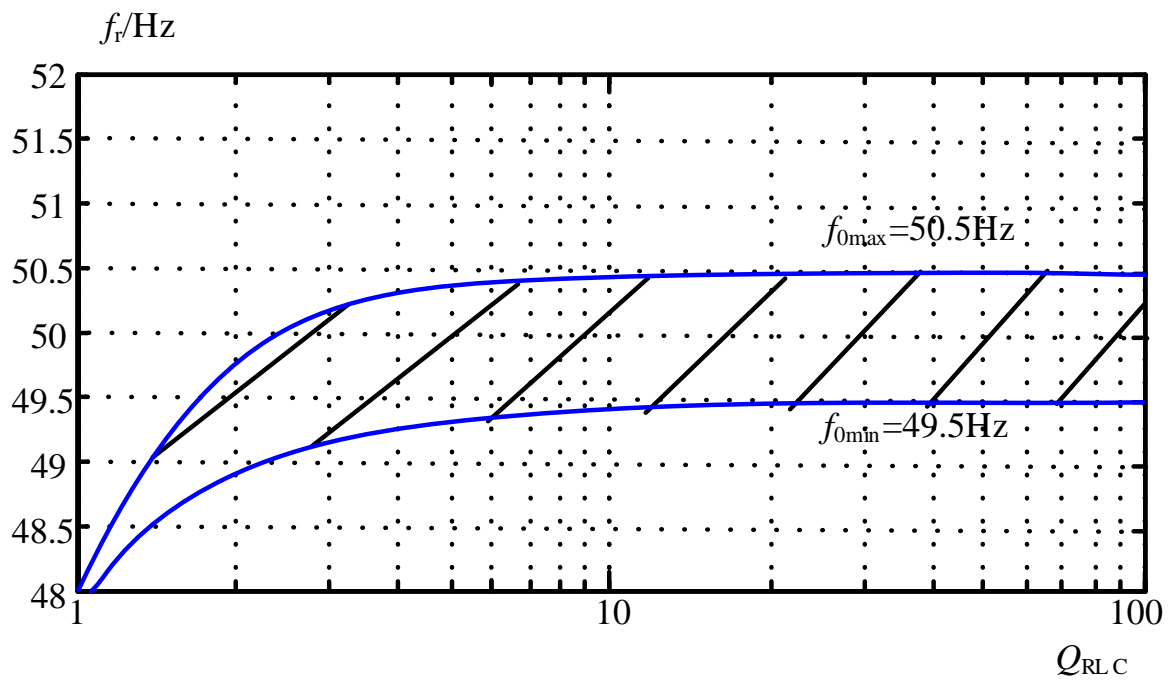

Figure 6. The non-detection zone (NDZ) of the islanding detection method.

\section{Elimination of the Non-Detection Zone}

According to the above analysis, to eliminate the NDZ, the range of $\Delta f_{0}$ can be set as follows:

$$
\left\{\begin{array}{l}
\Delta f_{0}<\frac{-g_{f}+\sqrt{g_{f}{ }^{2}-64 f_{0}\left(f_{0 \max }-f_{0 \min }\right)}}{16} \\
\Delta f_{0}>\frac{-g_{f}-\sqrt{g_{f} f^{2}-64 f_{0}\left(f_{0 \max }-f_{0 \min }\right)}}{16}
\end{array}\right.
$$

With the mentioned parameters, if $\Delta f_{0}$ is $0.2 \mathrm{~Hz}$, the NDZ can be avoided. However, the larger $\Delta f_{0}$ is, the higher the current distortion is. For solving the problem, the NDZ elimination method has been proposed. The change of $\theta_{0}$ with and without the elimination method is shown in Figure 7.

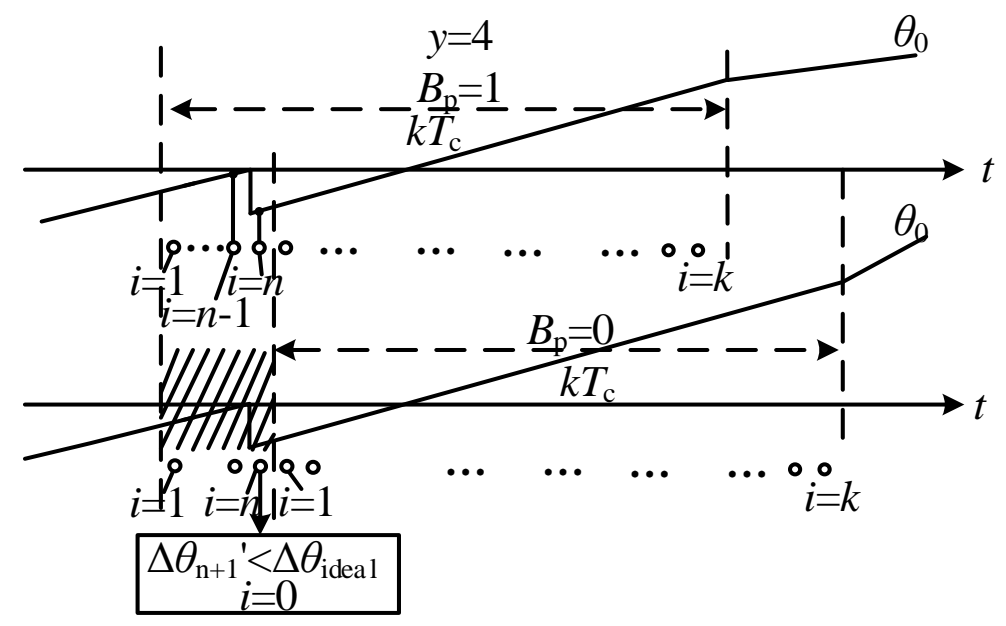

Figure 7. The change of $\theta_{0}$ with and without the NDZ elimination method.

The AC voltage phase difference between the two adjacent switching cycles is calculated every switching cycle. The allowed range is $\left[2 \pi T_{c} f_{0 \min }, 2 \pi T_{c} f_{0 \max }\right]$. If it exceeds the allowed range, $i$ would be cleared to 0 . If $i$ increases to $k$, the average value of $\Delta \theta$ is calculated. According to (1), the voltage 
frequency can be achieved. With this method, the voltage frequency can be the same as the current frequency. Thus, the NDZ can be eliminated. The essence of this method is to avoid the areas in which $B_{p}$ is 1 . Figure 7 corresponds to the area where $y$ is 4 , which is mentioned in Figure $5 \mathrm{~b}$. $\theta_{0}$ has a sudden change in this area. $\Delta \theta_{n+1}{ }^{\prime}$ is the AC voltage phase difference between the two adjacent switching cycles when $i$ is $n$. It is less than $2 \pi T_{c} f_{0 \mathrm{~min}}$. With the NDZ elimination method, $i$ would be cleared to 0 . As a result, the shadow area can be avoided. The calculated AC voltage frequency will not decrease by the sudden change of the phase angle.

Similarly, in the condition where the disturbance tends to decrease the current frequency, when $\Delta \theta_{n+1}{ }^{\prime}$ is larger than $2 \pi T_{c} f_{0 \max }, i$ is cleared to 0 and the NDZ can be eliminated.

\section{Simulation and Experimental Verification}

An $18 \mathrm{kVA}$ three-phase inverter was established based on MATLAB/Simulink. The grid is $220 \mathrm{~V} / 380 \mathrm{~V} / 50 \mathrm{~Hz}$. The switching frequency is $5 \mathrm{kHz}$.

Figure 8 shows the simulation results with the inductive load. The frequency disturbance is $0.5 \mathrm{~Hz}$. It tends to increase the current frequency. The parameters of the $R L C$ load are $8 \Omega, 0.5 \mathrm{mH}$, and $10 \mathrm{mF}$. The resonant frequency of it is $71.2 \mathrm{~Hz}$, and $k$ is 20 .

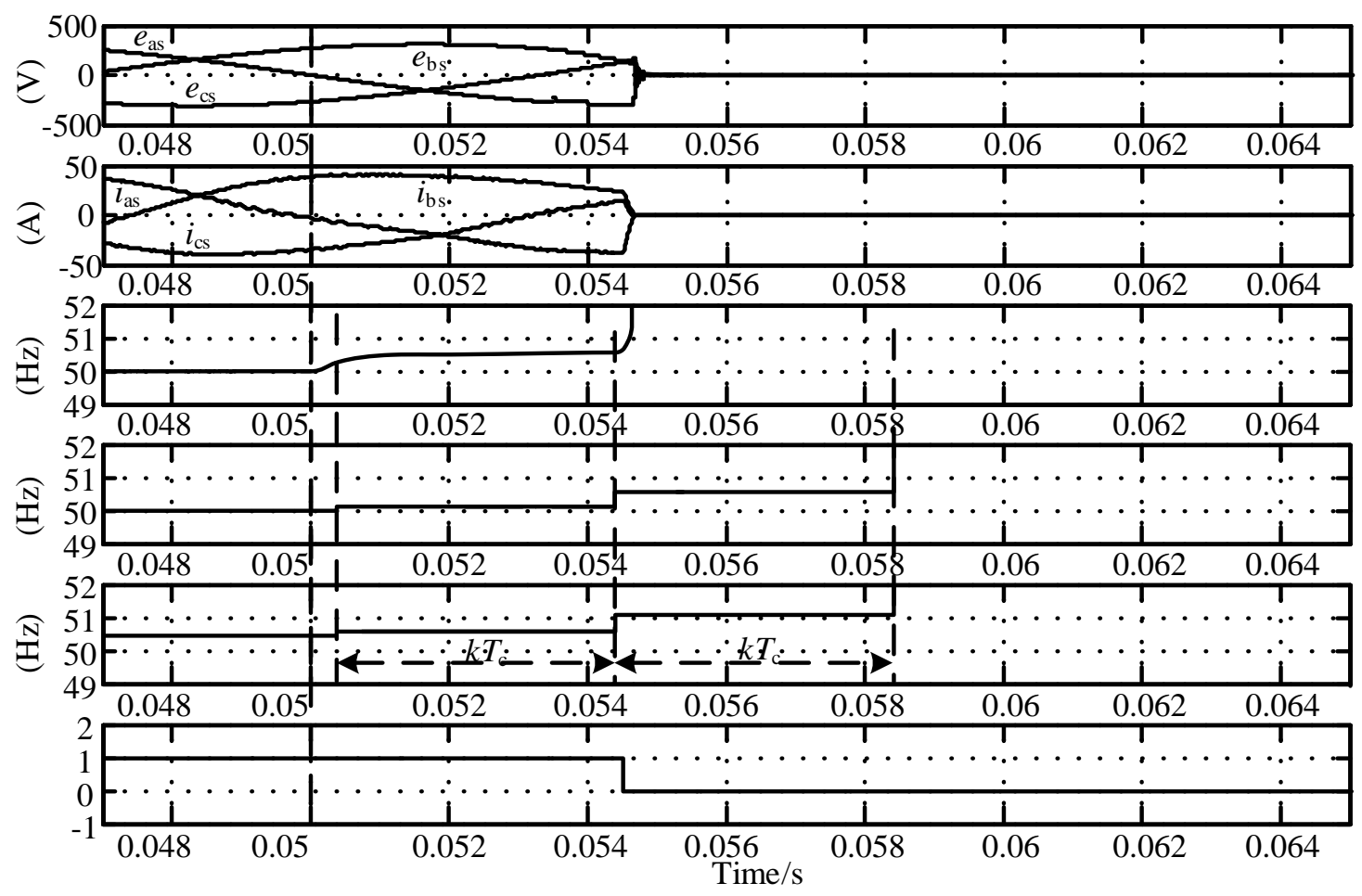

Figure 8. The simulation results with the inductive load.

The waveforms from top to bottom are the AC voltage and current, the real frequency of the $\mathrm{AC}$ voltage, the calculation frequency of the AC voltage, the reference of the current frequency, and the off-grid signal, respectively. The inverter becomes disconnected from the grid at the time $0.05 \mathrm{~s}$. Because the load is inductive, the disturbance will aggravate the frequency variation after the inverter is disconnected from the grid. According to the analysis, Figure 5a, and the Formula (16), the calculation frequency increases quickly. The islanding can be detected in a few disturbance cycles and the NDZ will not occur. The off-grid signal changes to 0 when the calculation frequency exceeds the allowed range. The inverter stops working.

Figure 9 shows the simulation results with the capacitive load. The parameters of the RLC load are $8 \Omega, 1.03 \mathrm{mH}$, and $10 \mathrm{mF}$. The resonant frequency of it is $49.6 \mathrm{~Hz}$. The quality factor of the load is 25. According to the theoretical analysis, NDZ will not occur when the frequency disturbance is 
$0.5 \mathrm{~Hz}$. Therefore, the disturbance is $0.1 \mathrm{~Hz}$. The waveforms from top to bottom are the AC voltage and current, the real frequency of the $\mathrm{AC}$ voltage, the calculation frequency of the $\mathrm{AC}$ voltage, the reference of the current frequency, and the off-grid signal, respectively. The inverter becomes disconnected from the grid at the time $0.05 \mathrm{~s}$. The calculated frequency in the area that $y=n$ is just the real frequency in the area that $y=n-1$. In the area that $y$ is $5, \mathrm{ZCC}$ happens and the reference of the current frequency in the next disturbance cycle would decrease. The islanding happens, which is shown in Figure 9a. In Figure 9b, the NDZ estimation method is applied. The shadow area in Figure $9 b$ is the cause of the NDZ. By detecting the phase angle change and clearing the counter, the shadow area can be avoided, and the islanding can be detected.

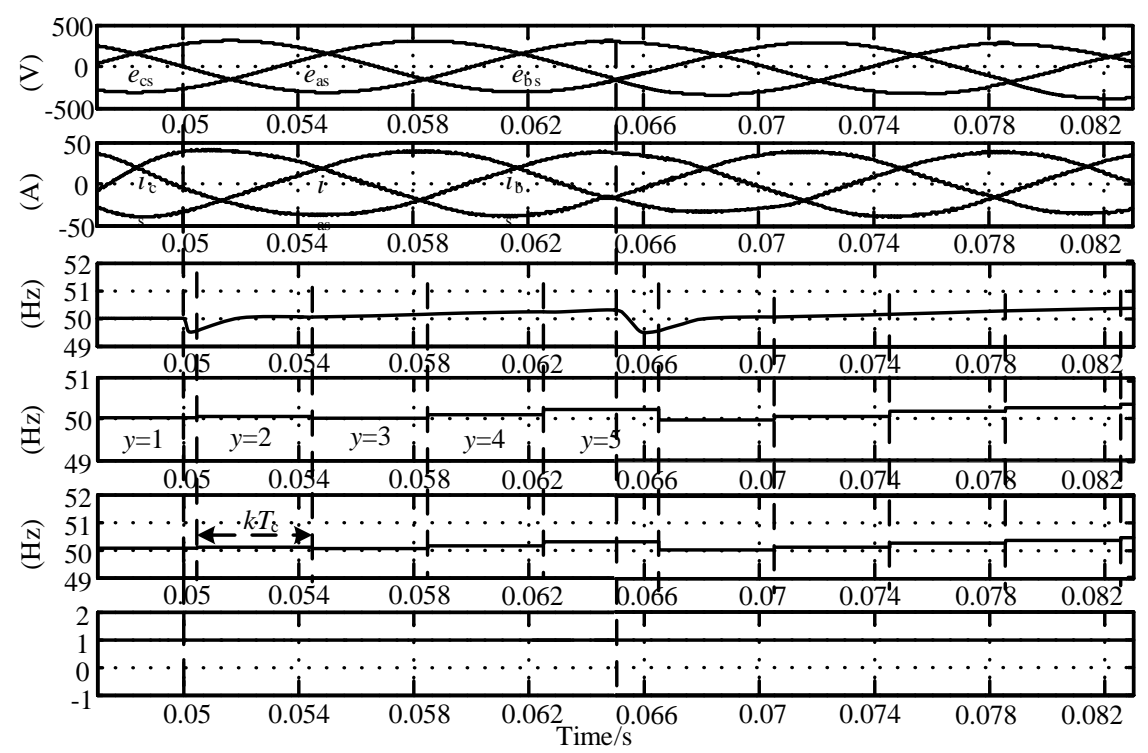

(a)

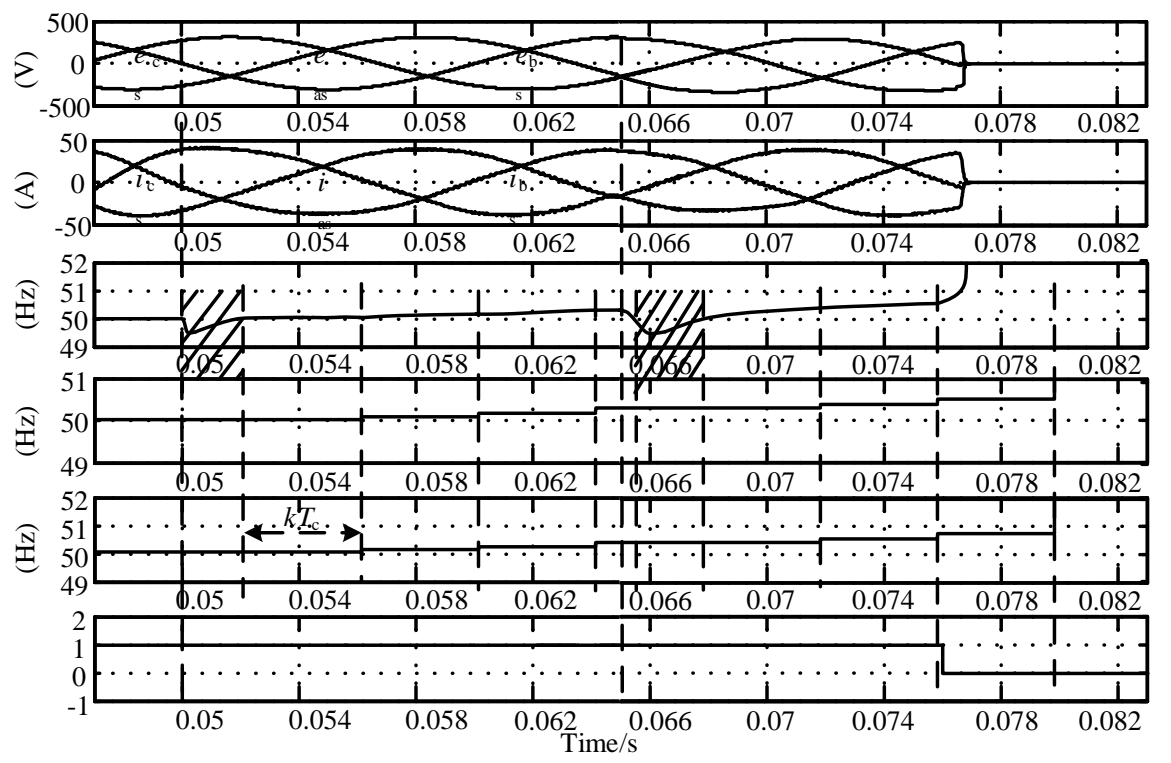

(b)

Figure 9. The simulation results with the capacitive load. (a) Without the NDZ estimation method. (b) With the NDZ estimation method.

A principle prototype is established. The parameters are the same as that of the simulation. Figure 10 shows the connection mode of the inverter system. 


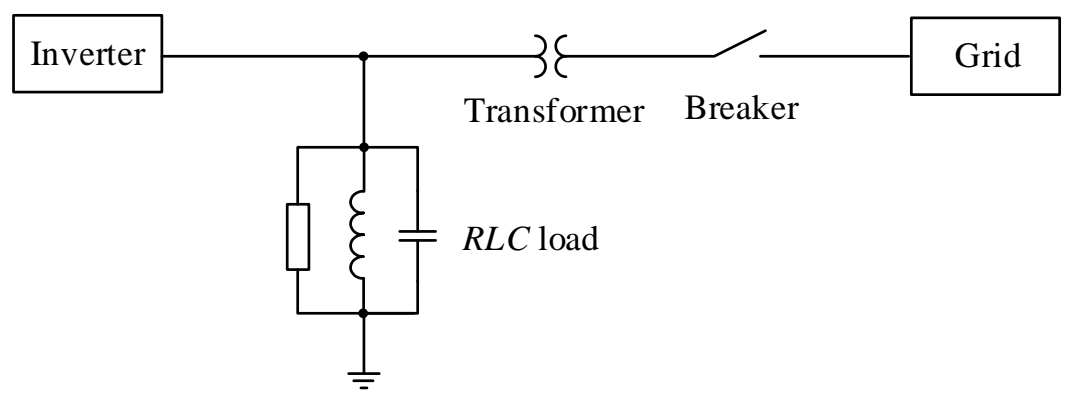

Figure 10. The connection mode of the inverter system.

Figure 11 shows the experimental results with the inductive load. The frequency disturbance is $0.1 \mathrm{~Hz}$. The parameters of the RLC load are the same as that of Figure 8 . The waveforms respectively are the AC current and voltage. The inverter becomes disconnected from the grid at time $t_{0}$. Because the load is inductive, the disturbance will aggravate the frequency variation after the inverter is disconnected from the grid. The islanding can be quickly detected. At this time, the inverter stops working and the reliability of the system is guaranteed. The result is consistent with the simulation result that is shown in Figure 8.

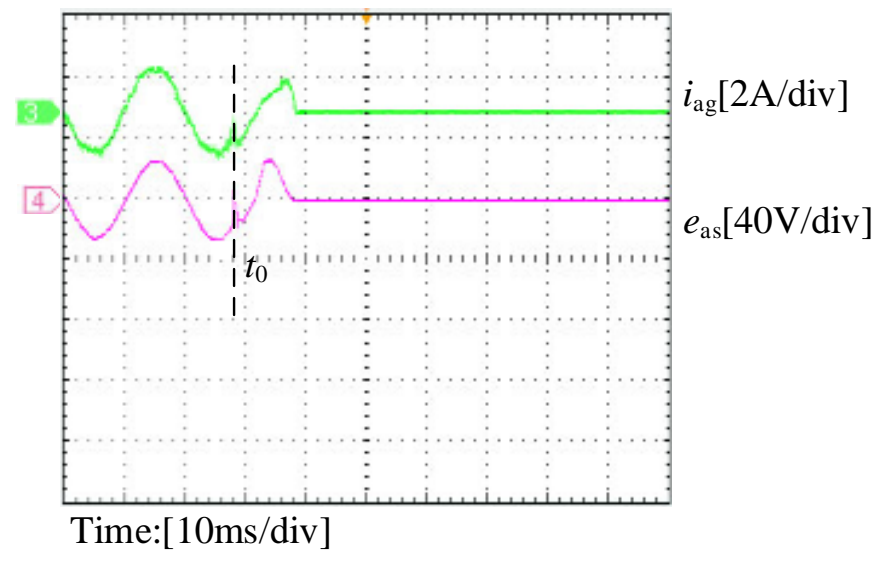

Figure 11. The experimental results with the inductive load.

Figure 12 shows the experimental results with the capacitive load. The frequency disturbance is $0.1 \mathrm{~Hz}$. The parameters of the RLC load are the same as that of Figure 9. The islanding cannot be detected without the NDZ estimation method. In Figure 9b, the NDZ estimation method is added and the islanding can be detected quickly. The result is consistent with the simulation result that is shown in Figure 9.

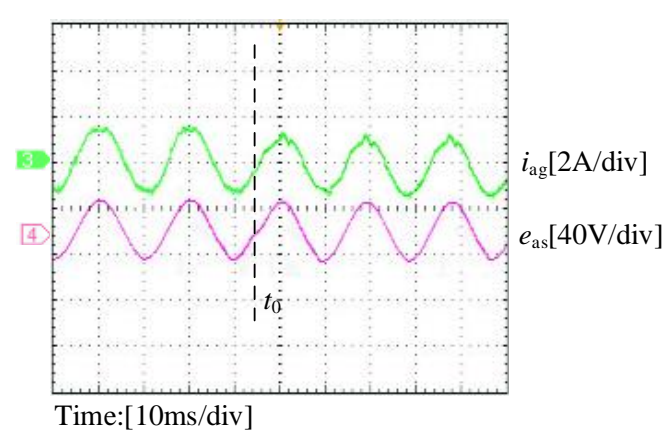

(a)

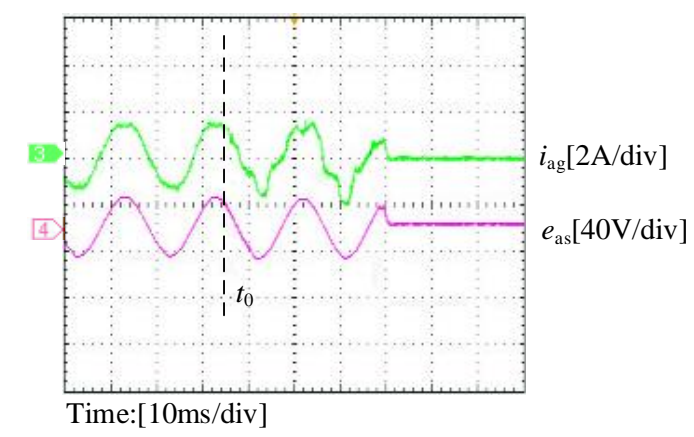

(b)

Figure 12. The experimental results with the capacitive load. (a) Without the NDZ estimation method. (b) With the NDZ estimation method. 
Figure 13 shows the experimental results when the inverter is connected to the grid. In Figure 13a, the waveforms are the $\mathrm{AC}$ voltage, the disturbed phase angle, and the AC current, respectively. The disturbance is $0.1 \mathrm{~Hz}$. When the phase angle crosses zero, the corresponding current waveform remains for a short time. Figure 13b shows the harmonic spectrum of the AC voltage and current. The filter with the inductance-capacitance- inductance structure, which is defined as LCL filter, is applied and their parameters are $0.9 \mathrm{mH}, 1.5 \mathrm{mH}$, and $20 \mu \mathrm{F}$, respectively. In phase a, the Total Harmonic Distortion (THD) of the current is 3.8\%. It can be seen that the current harmonic distortion is low when the inverter is working normally, which satisfies the requirement of the grid connection.

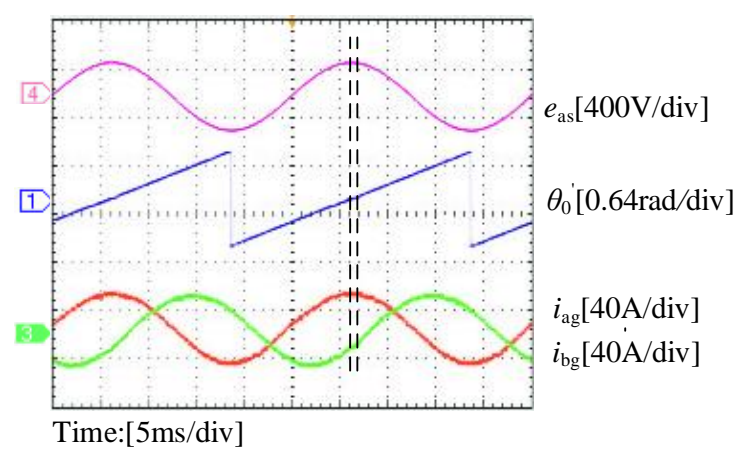

(a)

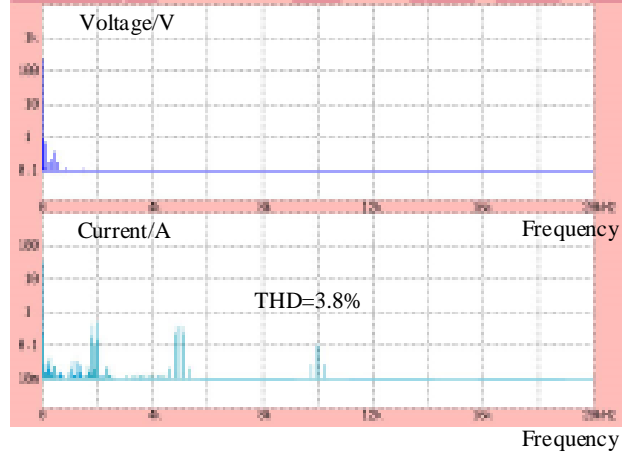

(b)

Figure 13. The experimental results when the inverter is connected with the grid. (a) The voltage and current waveforms. (b) The harmonic spectrum of the voltage and current.

Table 1 shows the phase angles and THDs of the three-phase current when the inverter is connected to the grid. In phases b and c, the THDs are $4.7 \%$ and $4.8 \%$, respectively. They are both in the allowed range.

Table 1. The phase angles and THDs of the three-phase current.

\begin{tabular}{cccc}
\hline Parameters & $\boldsymbol{i}_{\mathrm{ag}}$ & $\boldsymbol{i}_{\mathrm{bg}}$ & $\boldsymbol{i}_{\mathrm{cg}}$ \\
\hline Phase Angle $^{\circ}$ & -3.0 & 237.5 & 117.5 \\
THD $/ \%$ & 3.8 & 4.7 & 4.8 \\
\hline
\end{tabular}

Figure 14 shows the change of the three-phase THDs with different frequency disturbances. The higher the frequency disturbance, the higher are the THDs. With the proposed method, the distortion of phase a is less than that of the other phases.

$\mathrm{THD} / \%$

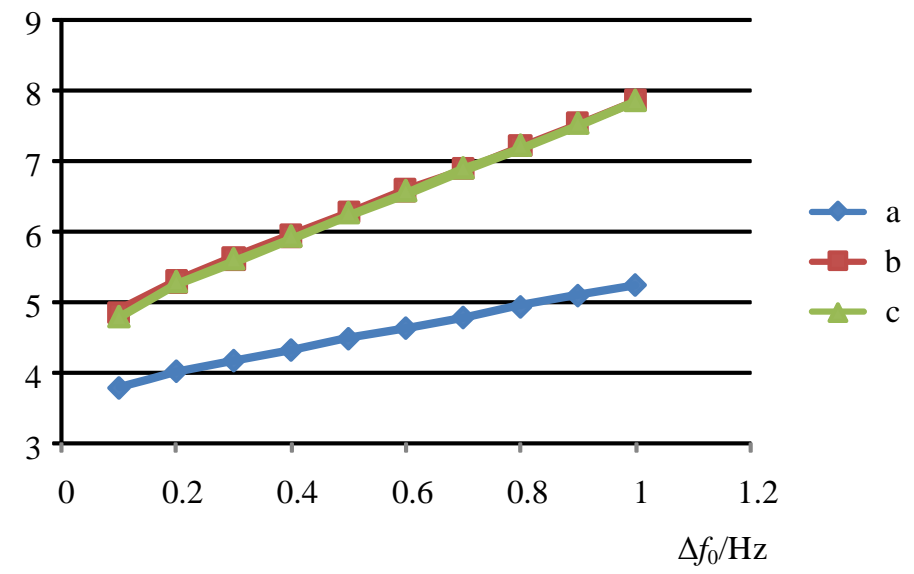

Figure 14. The change of three-phase THDs with different frequency disturbances. 
Table 2 shows the response speed of the proposed detection method with different load conditions. It can be seen that the islanding can be quickly detected.

Table 2. The response speed with different load conditions.

\begin{tabular}{ccccc}
\hline No. & $\boldsymbol{R} / \boldsymbol{\Omega}$ & $\boldsymbol{L} / \mathbf{m H}$ & $\boldsymbol{C} / \mathbf{m F}$ & Response Speed $/ \mathbf{s}$ \\
\hline 1 & 8 & 0.5 & 10 & 0.006 \\
2 & 8 & 1.01 & 10 & 0.012 \\
3 & 8 & 1.02 & 10 & 0.015 \\
4 & 8 & 1.03 & 10 & 0.028 \\
5 & 8 & 1.1 & 10 & 0.009 \\
\hline
\end{tabular}

\section{Conclusions}

This paper proposes an improved AFD method with NDZ elimination, which can be used in the three-phase inverter system based on digital control. The calculated voltage frequency is updated every disturbance cycle and the disturbance can be a small value with the NDZ elimination method. The current distortion is low when the inverter works normally. The proposed method is sensitive and it has a higher detection speed. Furthermore, the disturbance only needs to be added to the phase angle in the proposed method instead of adding disturbances to all of the three phases; thus, the control system can be simplified. Compared to the impedance estimation-based methods, false judgment is less likely to happen.

Author Contributions: Conceptualization: X.Z.; Methodology: R.Z.; Software: X.C., N.S.

Funding: This research was funded by [the National Natural Science Foundation] grant number [51607052].

Conflicts of Interest: The authors declare no conflict of interest.

\section{References}

1. Guzman, R.; de Vicuna, L.G.; Castilla, M.; Miret, J.; Martin, H. Variable Structure Control in Natural Frame for Three-Phase Grid-Connected Inverters with LCL Filter. IEEE Trans. Power Electron. 2018, 33, 4512-4522. [CrossRef]

2. Muda, H.; Jena, P. Phase angle-based PC technique for islanding detection of distributed generations. IET Renew. Power Gener. 2018, 12, 735-746. [CrossRef]

3. Jia, K.; Wei, H.S.; Bi, T.S.; Thomas, D.W.P.; Sumner, M. An Islanding Detection Method for Multi-DG Systems Based on High-Frequency Impedance Estimation. IEEE Trans. Sustain. Energy 2017, 8, 74-83. [CrossRef]

4. Bayrak, G.; Kabalci, E. Implementation of a new remote islanding detection method for wind-solar hybrid power plants. Renew. Sustain. Energy Rev. 2016, 58, 1-15. [CrossRef]

5. Zheng, X.X.; Xiao, L.; Qin, W.W.; Zhang, Q. A New Islanding Detection Method based on the Feature Recognition Technology. J. Power Electron. 2016, 16, 760-768. [CrossRef]

6. Haider, R.; Kim, C.H.; Ghanbari, T.; Bukhari, S.B.A.; Zaman, M.S.U.; Baloch, S.; Oh, Y.S. Passive islanding detection scheme based on autocorrelation function of modal current envelope for photovoltaic units. IET Gener. Transm. Distrib. 2018, 12, 726-736. [CrossRef]

7. Biaz, B.M.; Ferreira, V.H.; Fortes, M.Z.; Lopes, T.T.; Lima, G.B.A. Islanding Detection in Distributed Generation using Unsupervised Learning Techniques. IEEE Latin Am. Trans. 2018, 16, 118-125. [CrossRef]

8. Pinto, S.J.; Panda, G. Performance evaluation of WPT based islanding detection for grid-connected PV systems. Int. J. Electr. Power Energy Syst. 2016, 78, 537-546. [CrossRef]

9. Petrella, R.; Revelant, A.; Stocco, P. Advances on inter-harmonic variable-frequency injection-based grid-impedance estimation methods suitable for PV inverters. In Proceedings of the 2009 IEEE Energy Conversion Congress and Exposition (ECCE 2009), San Jose, CA, USA, 20-24 September 2009.

10. Garcia, P.; Sumner, M.; Navarro-Rodriguez, A.; Guerrero, J.M.; Garcia, J. Observer-Based Pulsed Signal Injection for Grid Impedance Estimation in Three-Phase Systems. IEEE Trans. Ind. Electron. 2018, 65, 7888-7899. [CrossRef]

11. Keawthai, S.; Po-Ngam, S. Simplified active power and reactive power control with MPPT and islanding detection for three-phase grid-connected photovoltaic inverters. In Proceedings of the 2015 12th International Conference on Electrical Engineering/Electronics, Computer, Telecommunications and Information Technology (ECTI-CON), Hua Hin, Thailand, 24-27 June 2015. 
12. Mohamad, A.M.I.; Mohamed, Y.A.R.I. Analysis and Mitigation of Interaction Dynamics in Active DC Distribution Systems With Positive Feedback Islanding Detection Schemes. IEEE Trans. Power Electron. 2018, 33, 2751-2773. [CrossRef]

13. Das, P.P.; Chattopadhyay, S. A Voltage-Independent Islanding Detection Method and Low-Voltage Ride Through of a Two-Stage PV Inverter. IEEE Trans. Ind. Appl. 2018, 54, 2773-2783. [CrossRef]

14. Patrao, I.; González-Medina, R.; Marzal, S.; Garcera, G.; Figueres, E. Synchronization of Power Inverters in Islanded Microgrids Using an FM-Modulated Signal. IEEE Trans. Smart Grid. 2017, 8, 503-510. [CrossRef]

15. Mazhari, I.; Beghou, L.; Enslin, J.; Parkhideh, B.; Bhowmik, S. Locking frequency band exposure method for islanding detection and prevention in distributed generation. In Proceedings of the 2014 IEEE Energy Conversion Congress and Exposition (ECCE), Pittsburgh, PA, USA, 14-18 September 2014.

16. Chen, X.L.; Li, Y.L. An Islanding Detection Method for Inverter-Based Distributed Generators Based on the Reactive Power Disturbance. IEEE Trans. Power Electron. 2016, 31, 3559-3574. [CrossRef]

17. Mohanty, S.R.; Kishor, N.; Ray, P.K.; Catalao, J.P.S. Comparative study of advanced signal processing techniques for islanding detection in a hybrid distributed generation system. IEEE Trans. Sustain. Energy 2015, 6, 122-131. [CrossRef]

18. Manohar, M.; Koley, E.; Ghosh, S. Reliable protection scheme for PV integrated microgrid using an ensemble classifier approach with real-time validation. IET Sci. Meas. Technol. 2018, 12, 200-208. [CrossRef]

19. Dong, D.; Wen, B.; Mattavelli, P.; Boroyevich, D.; Xue, Y.S. Modeling and design of islanding detection using phase-locked loops in Three-Phase grid-interface power converters. IEEE J. Emergy Sel. Top. Power Electron. 2014, 2, 1032-1040. [CrossRef]

20. Bakhshi, R.; Sadeh, J. Voltage positive feedback based active method for islanding detection of photovoltaic system with string inverter using sliding mode controller. Sol. Energy 2016, 137, 564-577. [CrossRef]

21. Serban, E.; Pondiche, C.; Ordonez, M. Islanding Detection Search Sequence for Distributed Power Generators Under AC Grid Faults. IEEE Trans. Power Electron. 2015, 30, 3106-3121. [CrossRef]

22. Munoz-Cruzado-Alba, J.; Villegas-Nunez, J.; Vite-Frias, J.A.; Carrasco-Solis, J.M.; Galvan-Diez, E. New Low-Distortion-Droop Plus Correlation Anti-Islanding Detection Method for Power Converters in Distributed Generation Systems. IEEE Trans. Ind. Electron. 2015, 62, 5072-5081. [CrossRef]

23. Liu, M.; Zhao, W.; Huang, S.; Wang, Q.; Shi, K. Problems in the Classic Frequency Shift Islanding Detection Methods Applied to Energy Storage Converters and a Coping Strategy. IEEE Trans. Energy Convers. 2018, 33, 496-505. [CrossRef]

24. Yafaoui, A.; Wu, B.; Kouro, S. Improved active frequency drift anti-islanding detection method for grid connected photovoltaic systems. IEEE Trans. Power Electron. 2012, 27, 2367-2375. [CrossRef]

25. Samet, H.; Hashemi, F.; Ghanbari, T. Minimum non detection zone for islanding detection using an optimal Artificial Neural Network algorithm based on PSO. Renew. Sustain. Energy Rev. 2015, 52, 1-18. [CrossRef]

26. Kim, B.-H.; Sul, S.-K. Comparison of Non-Detection Zone of frequency drift anti-islanding with closed-loop power controlled Distributed Generators. In Proceedings of the 2015 IEEE 2nd International Future Energy Electronics Conference (IFEEC), Taipei, Taiwan, 1-4 November 2015.

27. Liu, S.J.; Zhuang, S.X.; Xu, Q.; Xiao, J. Improved voltage shift islanding detection method for multi-inverter grid-connected photovoltaic systems. IET Gener. Transm. Distrib. 2016, 10, 3163-3169. [CrossRef]

28. Hasan, R.; Mekhilef, S.; Seyedmahmoudian, M.; Horan, B. Grid-connected isolated PV microinverters: A review. Renew. Sustain. Energy Rev. 2017, 67, 1065-1080. [CrossRef]

29. Ge, Y.Y.; Sun, J.J.; Gang, W.; Gao, Z.Q.; Li, Y. Improved Active Frequency Drift Anti-Islanding Detection Method. In Proceedings of the 2015 International Conference on Materials Engineering and Information Technology Applications (MEITA), Guilin, China, 30-31 August 2015.

30. Guo, X.Q.; Wang, H.B.; Zhang, Y.; San, G.C. Experimental verification of a new positive feedback islanding detection method for grid-connected inverter. J. Eng. Res. 2016, 4, 85-94.

31. Lee, K.J.; Lee, J.P.; Shin, D.; Yoo, D.W.; Kim, H.J. A Novel Grid Synchronization PLL Method Based on Adaptive Low-Pass Notch Filter for Grid-Connected PCS. IEEE Trans. Ind. Electron. 2014, 61, $292-301$. [CrossRef]

(C) 2018 by the authors. Licensee MDPI, Basel, Switzerland. This article is an open access article distributed under the terms and conditions of the Creative Commons Attribution (CC BY) license (http://creativecommons.org/licenses/by/4.0/). 